\title{
Pengelolaan Jadwal Absensi Dengan Mempergunakan RFID Dan Microcontroller Studi Kasus : Lab Teknik Informatika Universitas Suryakancana
}

\author{
Hasbu Na'im Syadad ${ }^{1}$, Andy Supriyandi ${ }^{2}$ \\ Program Studi Teknik Informatika \\ Fakultas Teknik Universitas Suryakancana Cianjur \\ hasbunaimsyadad@unsur.ac.id ${ }^{1}$, andysupriyadi@gmail.com ${ }^{2}$
}

\begin{abstract}
Abstrak
Perangkat controller dapat membantu pekerjaan sehari - hari manusia, dengan alat tersebut sebagian besar aktivitas dapat dilakukan dengan lebih praktis. Arduino merupakan sebuah platform yang terdiri dari hardware dan software. Hardware itu sendiri yang disebut microcontroller kemudian software-nya adalah sebuah IDE Arduino yang digunakan untuk memprogram input dan output dari modul Arduino.Pengelolaan absensi adalah salah satu sistem yang pada saat ini sangat banyak di butuhkan seiring banyak nya populasi manusia yang harus ter-data. Tetapi Sistem absensi yang kebanyakan saat ini digunakan yaitu masih melakukan dengan cara konvensional seperti tanda tangan untuk mengisi kehadiran dengan cara ini maka banyak sekali celah kecurangan yang sering terjadi. Dengan memanfaatkan sebuah alat menggunakan microcontroller, Menggabungkan Arduino dengan RFID, aplikasi, dan LCD yang nantinya akan mengelola laboraturium dengan alat tersebut, disaat melakukan absensi mahasiswa harus menginputkan kartu ID CARD ke alat tersebut dan nanti informasi absensi akan muncul di LCD.
\end{abstract}

Kata Kunci : Absensi, Microcontroller Arduino, RFID, Sublime text, Xampp

\section{Pendahuluan}

\section{Latar Belakang}

Disadari atau tidak, Perkembangan teknologi mengalami perubahan yang sangat cepat. Kemajuan teknologi berdampak pada pekerjaan manusia. Perkerjaan yang biasanya dilakukan oleh manusia menjadi dapat dilakukan oleh suatu sistem secara otomatis. Manusia menggunakan teknologi sebagai alat kemudahan untuk melakukan proses pengelolaan data. Hal ini ditunjukkan dengan banyaknya populasi manusia yang harus ter-data dengan teknologi sistem elektronik Contohnya seperti E-KTP (Electronic-Kartu Tanda Penduduk). Agar dapat dengan mudah memonitoring banyak populasi manusia. Dengan adanya teknologi seperti itu dapat mencegah berbagai kecurangan atau memanipulasi data sehingga tidak ada pihak yang dirugikan.

Dalam meninjau situasi dilapangan tersebut dapat di monitoring dengan teknologi perangkat controller. Controller yang digunakan dalam dunia robotika dan elektronika sering disebut "Mikrokontroller" yaitu sebuah chip yang berfungsi sebagai pengontrol rangkaian elektronik dan umunya dapat menyimpan program di dalamnya, Jadi disebut komputer mikro karena dalam IC atau chip mikrokontroller terdiri dari CPU, memory, dan I/O yang bisa kita kontrol dengan memprogramnya (Ardianto,P.Syaiful,N,A.Yusnidah 2015). I/O juga sering disebut dengan GPIO (General Purpose Input Output Pins) yang berarti : pin yang bisa kita program sebagai input atau output sesuai kebutuhan (Santoso 2015).

Salah satu teknologi mikrokontroller yang populer adalah arduino. Arduino merupakan pengendali mikro single-board yang bersifat open source, dirancang untuk memudahkan pengguna elektronik dalam berbagai bidang, merupakan "platform" hardware terbuka yang ditunjukan kepada siapa saja yang ingin membuat peralatan elektronik interaktif berdasarkan hardware dan software yang fleksibel dan mudah digunakan. Arduino tidak hanya sekedar sebuah alat pengembangan, tetapi ia adalah kombinasi dari hardware, bahasa pemrograman dan Integrated Development Environment (IDE) yang canggih.

IDE adalah sebuah software yang sangat berperan untuk menulis program, meng-compile menjadi kode biner dan meng-upload ke dalam memory microcontroller (Banzi, M 2008).Teknologi RFID (Radio frequency identification) adalah merupakan teknologi yang dapat melakukan many-to-many communication (banyak reader dapat membaca satu tag, maupun satu reader banyak membaca banyak tag), transmisi data secara wireless dibandingkan dengan barcode konvesional yang menggunakan optic. Dengan kelebihannya tersebut teknologi RFID dapat diimplementasikan juga sebagai media pendukung dalam kelancaran proses perkuliahan (Eko \& Bobi 2015).

Pencatatan absensi mahasiswa merupakan salah satu faktor terpenting pengelolan data di suatu Perguruan Tinggi, di kampus Universitas Suryakancana masih mengunakan sistem absensi secara manual dengan mengunakan kertas dan pena dizaman yang terus berkembang cepat seperti ini yang seharusnya sudah mengunakan absensi berteknologi atau otomatis, sistem absensi manual memiliki banyak kekurangan dan tidak efektif, yang seharusnya pihak dari kampus tersebut melakukan tindakan cepat dengan mengubahnya ke 
dalam bentuk sistem absensi otomatis .Perihal tidak cepat dalam sistem ini dapat berupa aliran proses data perekapan ke bagian server yang mengelola absensi mahasiswa yang harus melewati beberapa proses karena dilakukan secara manual, data absensi di bagian server absensi tidak dapat langsung di-update dan kemudian muncul hasilnya. Salah satu kekurangan sistem manual ini banyak sekali terjadi kecurangan dalam pengisian absensi yang dilakukan oleh mahasiswa, mahasiswa yang tidak hadir dapat memiliki tanda tangan dalam lembar absensi pada perkulihan di hari itu. Selain itu, sistem absensi manual tidak dapat memantau waktu kehadiran mahasiswa dan disini juga banyak sekali kecurang-kecurangan yang terjadi.

Pemantauan waktu kehadiran sangat berguna untuk megamati kebiasan hadir mahasiswa untuk meningkatkan kedisiplinan. Berdasarkan permasalahan diutamakan diperlukan pengembangan dari sistem perangkat Controller yang dapat melakukan monitoring di saat jam masuk dan pulang kuliah. Sistem Monitoring absensi yang akan di kembangkan harus memberikan tingkat keamanan yang baik, keakuratan, kecepatan dalam mengalirkan data serta memberikan kemudahan bagi penggunanya, dapat berjalan secara baik dalam mengelolanyuntuk memberikan informasi yang akurat dan ter-update tidak memberikan ruang untuk kecurangan dan memanipulasi data tersebut dengan menggunakan Arduino, RFID beserta IDE untuk memprogram sistemnya dan menggunakan beberapa sensor-sensor untuk mendukung kinerja sistem.

\subsection{Rumusan Masalah}

Berdasarkan latar belakang yang sudah diketahui, rumusan masalahnya ialah bagaimana membuat sistem pengelolaan aplikasi absensi dosen dan mahasiswa menggunakan mikrokontroller Arduino dan RFID secara otomatis untuk meningkatkan tingkat kedisiplinan yang baik, pemantauan, dan cepat dalam mengalirkan data absensi ke bagian server yang mengelola absensi, serta memberikan kemudahan bagi penggunanya.

\subsection{Maksud dan Tujuan}

Maksud dari penelitian ini adalah membangun Sistem Monitoring Absensi Mahasiswa Berbasis Mikrokontroller Arduino. Dari produk yang dihasilkan melalui penelitian ini diharapkan akan menghasilkan tingkat keamanan yang baik, keakuratan, kecepatan dalam mengalirkan data serta memberikan kemudahan bagi penggunanya. Tujuan dari penelitian ini yaitu :

a. Mencatat waktu absensi mahasiswa dengan sangat akurat.

b. Memudahkan rekapitulasi harian dalam bentuk jumlah kehadiran masuk mahasiswa di kelas tersebut dengan ter-update.

c. Menghemat waktu dan kertas.

d. Membentuk mahasiswa agar lebih disiplin.

\subsection{Batasan Masalah}

Berikut merupakan permasalahan yang akan dibahas pada penelitian ini:

a. Merancang dan membuat sistem absensi otomatis. b. Pembangunan sistem masih berupa perancangan yang dapat menyajikan informasi data absensi mahasiswa memanfaatkan teknologi mikrocontroller arduino dan RFID (Radio frequency identification).

c. Diperuntukan untuk asisten dosen dan mahasiswa.

d. Akan diuji coba dilakukan di satu mata kuliah (Fakultas Teknik Informatika).

\section{Tinjauan Pustaka}

\subsection{Pengertian Pengelolaan}

Pengelolaan merupakan terjemahan dari kata management terbawa oleh derasnya arus penambahan kata pungut ke dalam bahasa Indonesia, istilah inggris tersebut lalu di Indonesia menjadi manajemen. Manajemen berasal dari kata diatur berdasarkan urutan dari fungsi-fungsi manajemen. Jadi manajemen itu merupakan suatu proses untuk mewujudkan tujuanyang di inginkan melalui aspek-aspeknya antara lain planning, organizing, actuating dan controlling (Daryanto, 1997).

\subsection{Absensi}

Absensi adalah suatu pendataan kehadiran, bagian dari pelaporan aktifitas suatu institusi, atau komponen institusi itu sendiri yang berisi data-data kehadiran yang disusun dan diatur sedemikian rupa sehingga mudah untuk dicari dan dipergunakan apabila sewaktu-waktu diperlukan oleh pihak yang berkepentingan.(Erna Simonna, 2009).

\subsection{Mikrokontroller}

Menurut Hari Santoso "mikrokontroller" adalah komputer yang berukuran mikro dalam satu chip IC (integrated circuit) yang terdiri dari processor, memory, dan antarmuka yang bisa diprogram" (Hari Santoso, 2015).

\subsection{Arduino}

Dalam bukunya, Feri Djuandi menerangkan bahwa "Arduino merupakan sebuah platform yang terdiri dari hardware dan software. Hardware itu sendiri yang disebut mikrokontroller kemudian software-nya adalah sebuah IDE Arduino yang digunakan untuk memprogram input dan output dari modul arduino" (Feri Djuanda, 2011). Arduino ini bersifat open source baik hardware maupun software, sehingga siapapun dapat mengembangkannya.

\section{Analisis Sistem}

Analisis sistem ini akan membahas mengenai analisis masalah, analisis kebutuhan fungsional, dan analisis kebutuhan nonfungsional. Pada penelitian dan perancangan monitoring absensi mahasiswa ini digunakan untuk memantau absensi mahasiswa berbasis microcontroller Arduino ini untuk memberikan informasi cepat kebagian server pengelola absensi, pada umumnya sistem absensi ini hanya melakukan tanda tangan untuk mengetahui kehadiran seorang mahasiswa.

\subsection{Analisis Masalah}

Absensi yang ada di Universitas Suryakacana masih banyak kekurangan, karena masih mengunakan cara konvensional, yang memungkinkan mahasiswa dapat 
melakukan kecurangan. Sehingga sering terjadi titip absen kepada rekannya, membuat mahasiswa menjadi kurang disiplin.

Untuk mengatasi permasalahan ini perlu dibuatnya sistem untuk absensi yaitu pengelolaan absensi mahasiswa yang dapat meminalisir kecurangan yang terjadi, tetapi sebuah system ini juga dapat memberikan informasi dengan mudah, cepat, akurat, dan realtime. Untuk membuat sistem ini dapat memanfaatkan perangkat microcontroller arduino untuk pembuatan monitoring absensi mahasiswa, microcontroller dapat digabungkan dengan modul sensor seperti RFID untuk membaca chip yang didekatkan ke alat tersebut, LED untuk mengetahui apakah input atau output sudah terbaca dengan otomatis, LCD untuk memberikan informasi apakah yang di inputkan itu berhasil atau tidak.

\subsection{Analisis Kebutuhan Fungsional}

Perangkat microcontroller yang dirancang harus memiliki fungsi utama yang menjadi solusi dari permasalahan yang ada pada sistem sebelumnya. Pada analisis kebutuhan fungsional mendefinisikan fungsi utama perangkat lunak sistem monitoring absensi mahasiswa, antara lain :

a. Pengelolaan jadwal perkuliahan

Sistem mengelola ini dapat mengontrol jadwal perkuliahan dilaboraturium secara otomatis ketika ada jadwal perkuliahan di hari itu.

b. Monitoring sistem keamanan

Sistem keamanan absensi ini akan dapat memonitoring dengan menggunakan RFID dengan ID berbeda pada setiap mahasiswa.

c. Antarmuka pengguna

Setiap informasi saat seorang mahasiswa mendekatkan kartu ID ke alat RFID akan ditampilkan pada layar LCD di depan untuk memberikan informasi apakah alat tersebut sudah membaca ID yang di tempelkan ke alat tersebut.

\subsection{Analisis Kebutuhan NonFungsional}

Analisis non funsional mendeskripsikan mengenai spesifikasi yang dibutuhkan sistem diluar dari fungsi yang tersedia pada sistem yang akan dibuat. Analisa Kebutuhan Non Funsional terdiri dari :

\subsubsection{Software}

Analisis perangkat lunak (Software) mendefinisikan perangkat lunak yang dibutuhkan untuk membangun sistem monitoring absensi mahasiswa. Software yang dibutuhkan antara lain :

- Sistem Operasi Windows

- IDE Arduino

- Sublime Text

- Balsmiq

- Visual paradigm

\subsubsection{Hardware}

Analisis perangkat keras (Hardware) mendefinisikan perangkat keras yang digunakan untuk membangun sistem monitoring absensi mahasiswa. Perangkat keras yang dibutuhkan antara lain :

- Arduino Uno
- Ethernet Shield

- Kabel RJ 45

- $\quad$ RFID (Radio Frequensi Identification)

- $\quad$ LCD (Liquid Crystal Display)

- Jumper

\subsection{Hasil Analisis}

Berdasarkan hasil analisis yang dilakukan, agar dapat pengelolaan absensi berbasis arduino ini di perlukan sebuah perangkat lunak untuk mengecek data yang masuk saat mahasiswa mendekatkan ID ke alat RFID tersebut, maka diperlukan sebuah rancangan alat bantu simulasi monitoring absensi mahasiswa mengunakan media konektivitas IDE dan kabel (RJ-45) dengan memanfaatkan microcontroller Arduino dan dibutuhkan perangkat lunak yang berfungsi sebagai pengecekan data absensi. Untuk menambahkan media konektivitas yaitu berupa IDE dan kabel $R J-45$ pada alat bantu simulasi monitoring absensi mahasiswa digunakan sebuah microcontroller Arduino yang akan menghubungkan IDE, RJ45 dan perangkat lunak. Dengan menggunakan IDE dan $R J-45$ tersebut akan dihubungkan dengan Arduino sebagai media konektivitas antara Arduino dengan perangkat lunak, kemudian Arduino akan terhubung dengan RFID, lcd dan Ethernet shield yang terdapat pada alat bantu monitoring absensi mahasiswa sehingga Arduino dapat merespon perintah yang dikirim melalui alat RFID yang kemudian diposes oleh microcontroller Arduino sehingga Arduino dapat memproses data dan langsung mengirimkanya ke perangkat lunak. Dengan begitu Arduino dan perangkat lunak telah berada pada media konektivitas yang sama yaitu jaringgan area local network.
3.4.1 Bahan (Hardware)
- Arduino Uno
- Ethernet Shield
- Kabel RJ 45
- RFID (Radio Frequensi Identification)
- LCD (Liquid Crystal Display)
- Jumper

\subsubsection{Alat (Software)}

- Sistem Operasi Windows

- Arduino IDE

- Sublime text

- Xampp

- Balsmiq

\section{Perancangan Sistem}

Perancangan sistem merupakan pengembangan sistem baru dari sistem yang telah ada, dimana pengembangan ini bertukuan untuk mengatasi permasalahan yang ditemui pada sistem yang lama. Pada tahap ini tentunya sudah diketahui permasalahan yang terjadi, sehingga pengembangan langsung dilakukan pada sistem yang baru.

\subsection{Perancangan Rangkaian Perangkat Keras}

Perancangan rangkaian perangkat keras merupakan perancangan yang digunakan untuk menjelaskan 
rangkaian perangkat keras secara keseluruhan dengan mengambarkan bagaimana perangkat satu dengan yang lainnya saling terhubung.

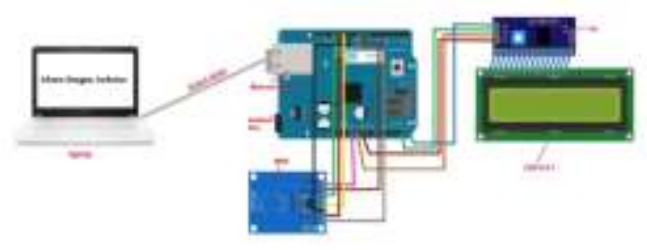

Gambar 1 Rancangan Perangkat Keras

\subsection{Perancangan Sistem}

\subsubsection{Flowchart Penginputan Admin}

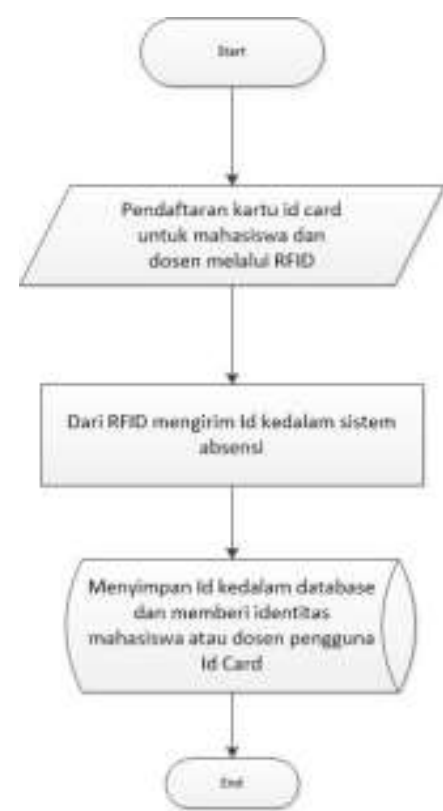

Gambar 1 Flowchart Penginputan Admin

\subsubsection{FlowchartPenginputan Mahasiswa}

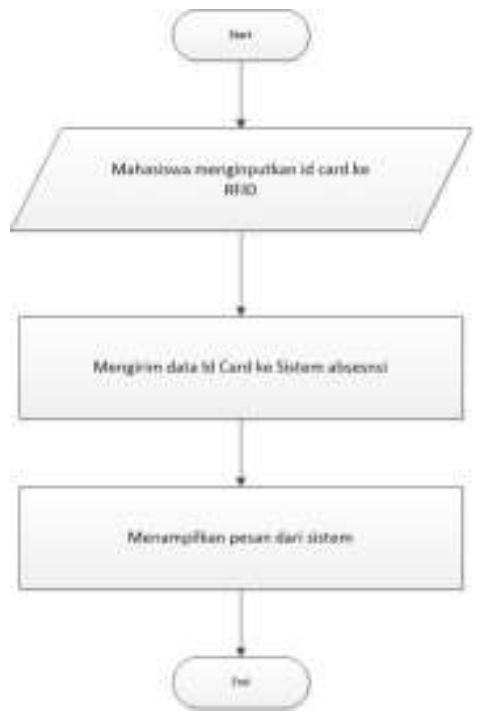

Gambar 2 FlowchartPenginputan Mahasiswa
Use Case Memperlihatkan hubungan antara aktor dan fungsi yang dapat dilakukan oleh aktor dalam ruang lingkup sistem.

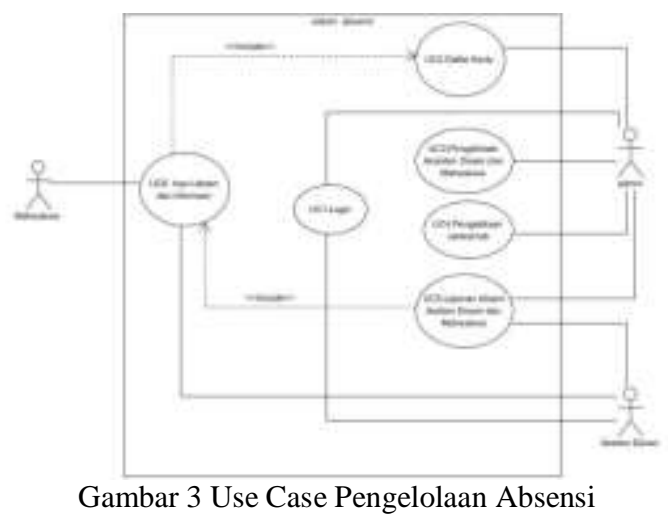

Activity diagram menggambarkan alur dari setiap aktifitas yang berjalan pada sebuah sistem, darimana aktifitas tersebut dimulai dan bagaimana aktifitas tersebut berakhir dengan melalui beberapa proses atau tahapan tertentu.

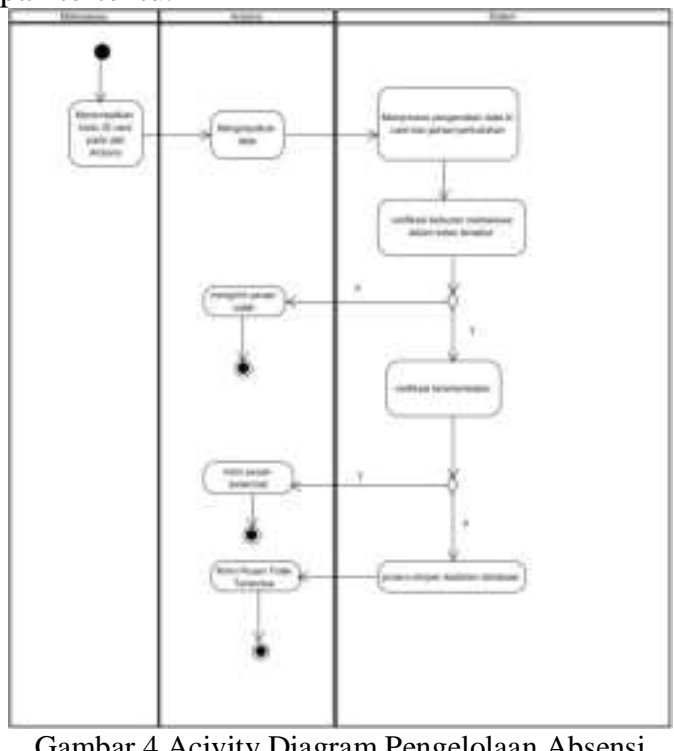

4.3 Perancangan Antarmuka Perangkat Lunak

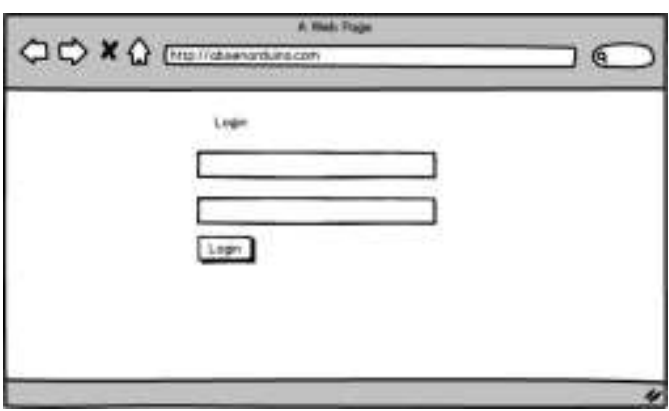

Gambar 5 Antar Muka Halaman Login 
Hasbu Na'im Syadad ${ }^{1}$ Andy Supriyandi ${ }^{2}$, Pengelolaan Jadwal Absensi Dengan Mempergunakan RFID dan Microcontroller Studi Kasus : Lab Teknik Informatika Universitas Suryakancana

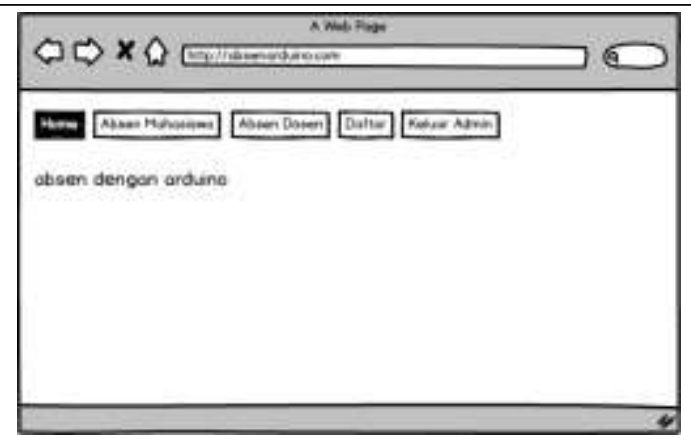

Gambar 6 Antar Muka Halaman Beranda

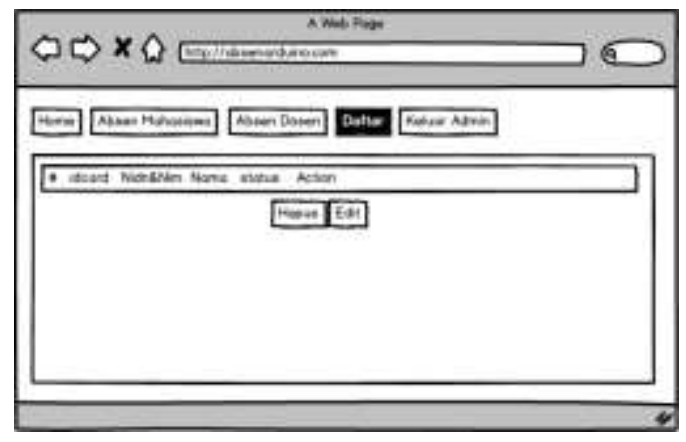

Gambar 7 Antar Muka Halaman Daftar

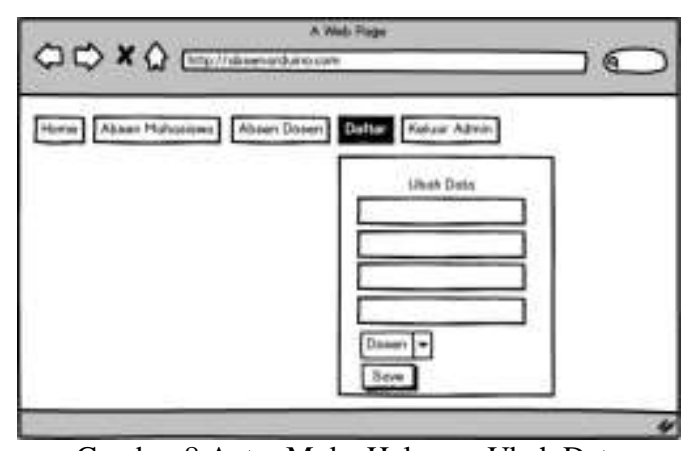

Gambar 8 Antar Muka Halaman Ubah Data

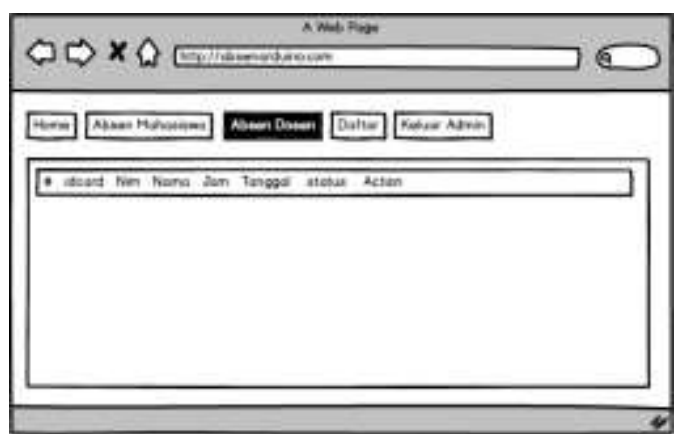

Gambar 9 Antarmuka Halaman Absen Asisten Dosen

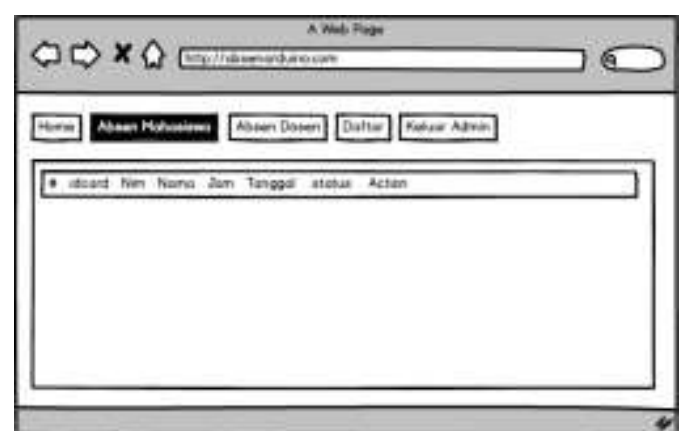

Gambar 10 Antar Muka Halaman Absen Mahasiswa

\subsection{Perancangan Antarmuka Hardware}

Perancangan antarmuka dilakukan untuk mempermudah dalam implementasi sistem yang akan dibangun. Tujuan dari perancangan antarmuka adalah memberi gambaran mengenai antarmuka pengguna yang digunakan pada sistem yang akan dibuat dan memperjelas alur program dari segi tampilan.

\section{Absen Waiting Server}

Gambar 11 Tampilan Layout Absen Waiting Server

Gambar 11 Tampilan Layout Layar Absensi Waiting Server tampilan awal saat absensi dinyalakan dan belum terkoneksi server.

\section{Absen $27 / 07 / 2018 \quad 08: 00$}

Gambar 12 Tampilan Layout absen saat sudah siap dipakai.

Gambar 12 Layout Tampilan absen sudah siap dipakai, tampilan absensi sudah bisa dipakai untuk proses absensi.

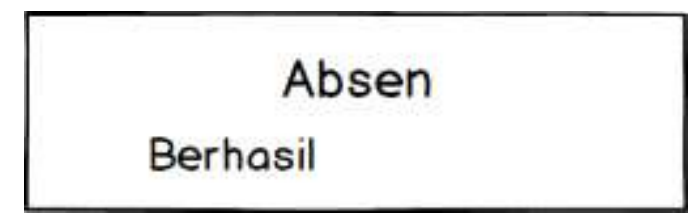

Gambar 13 Tampilan Layout absen berhasil

Gambar 13 Layout Tampilan absen berhasil, tampilan saat kartu id di dekatkan ke alat kemudian mengecek dan memberikan informasi ke LCD.

\subsection{Perancangan Model Visual Sistem}

Perancangan Visual dilakukan untuk mempermudah dalam implementasi sistem yang akan dibangun. Tujuan dari perancangan visual adalah memberi gambaran mengenai proses kepada pengguna sistem yang akan dibuat dan memperjelas alur program dari segi tampilan.

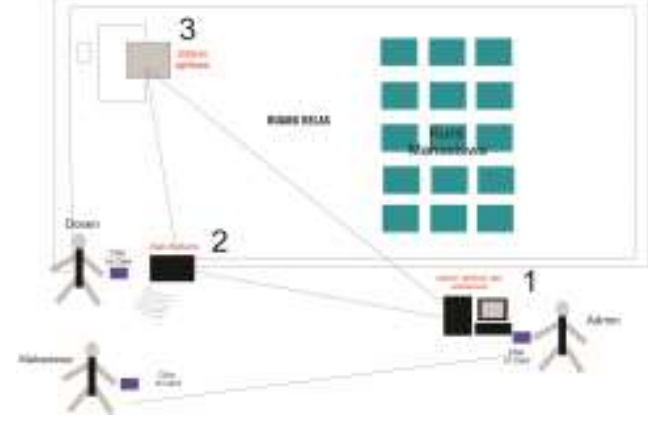

Gambar 14 Visual Pengelolaan Absensi 


\section{Implementasi Sistem 5.1 Perangkat Keras}

Pada tahap implementasi dan pengujian, perangkat keras yang digunakan adalah sebagai berikut :

a. Spesifikasi Komputer
- Prosessor
: Intel Celeron
- VGA
: Intel hd grapich
- RAM
: $2 \mathrm{~GB}$
- Harddisk : $500 \mathrm{~GB}$

b. Arduino Sistem Pengelolaan Absensi Mahasiswa

- Arduino Uno

- Kabel RJ-45

- Ethernet Shield

- Radio Frequensi Identification (RFID)

- LCD 16x2 (Liquid Crystal Display)

\subsection{Perangkat Lunak}

Perangkat lunak yang digunakan untuk membangun pengelolaan absensi mahasiswa dengan RFID dan Microcontroller (Studi Kasus Universitas Suryakancana), terdiri dari :

- Microsoft Windows 10, merupakan sistem operasi yang digunakan pada komputer yang membangun perintah-perintah (syntax) arduino.

- Visual Paradigm 8.0, aplikasi yang digunakan untuk membuat diagram-diagram yang digunakan dalam proses perancangan dan pemodelan sistem.

- Balsamiq Mockups, aplikasi yang digunakan untuk membuat perancangan tampilan antarmuka.

- Fritzing, aplikasi yang digunakan untuk membuat perancangan perangkat keras (hardware).

- Arduino IDE, aplikasi yang digunakan untuk sebagai editor dalam pemrograman/coding arduino.

- Sublime text, aplikasi editor untuk kode dan teks yang dapat berjalan diberbagai platform operating system dengan mengunakan teknologi phyton API.

- Xampp, aplikasi pengembang yang digunakan untuk pengembangan website berbasis PHP.

\subsection{Implementasi Antar Muka}

Implementasi antar muka monitoring absensi mahasiswa antar muka perangkat keras serta implementasi antar muka perangkat lunak. Berikut ini merupakan impelementasi antar muka dari monitoring absensi mahasiswa.

\subsubsection{Implementasi Antar Muka Perangkat Keras}

Berikut ini merupakan implementasi antar muka perangkat keras dari Monitoring Absensi Mahasiswa.

a. Implementasi Tampilan Awal Absensi saat belum terhubung dengan server. Implementasi Tampilan Awal Absensi merupakan tampilan awal pada saat perangkat pertama kali dinyalakan.

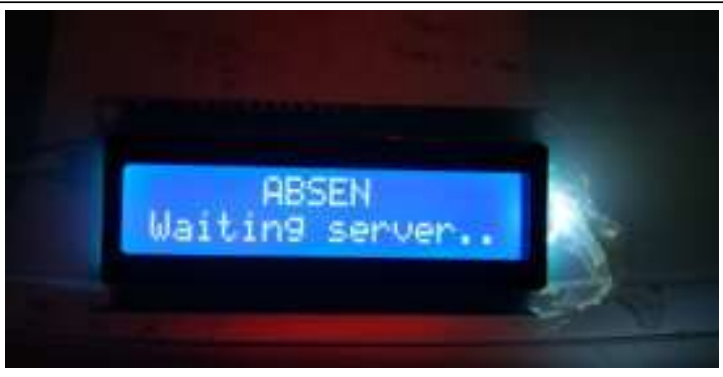

Gambar 15 Impelementasi Tampilan Awal Absensi saat belum terhubung dengan server

b. Implementasi Tampilan Awal Absensi saat proses absensi akan berjalan Implementasi Tampilan Awal Absensi merupakan tampilan awal pada saat perangkat akan digunakan untuk absensi.

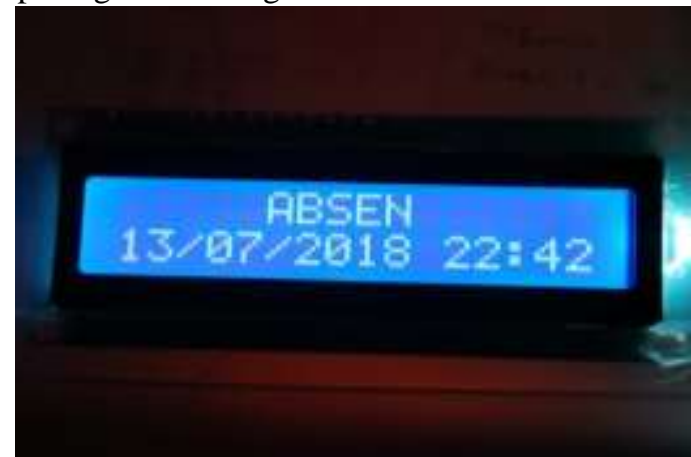

Gambar 16 Impelementasi Tampilan Awal Absensi saat proses absensi akan berjalan

c. Implementasi Tampilan Saat Proses Absensi Berhasil. Implementasi Tampilan Saat Proses Absensi merupakan tampilan pada saat kartu Id card di dekatkan ke RFID dan munculah tulisan di LCD tersebut.

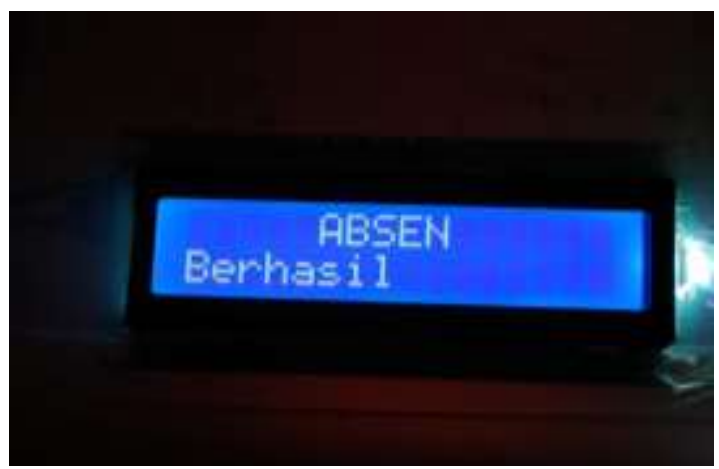

Gambar 17 Impelementasi Tampilan Proses Absensi Berhasil

\subsubsection{Implementasi Antar Muka Perangkat Lunak}

a. Implementasi Antar Muka Halaman login. Implementasi Halaman login yang digunakan oleh Dosen dan Admin dalam proses login kedalam sistem. 
Gambar 18 Impelementasi Antar Muka Halaman Login

b. Implementasi Antar Muka Halaman Utama Admin. Implementasi halaman utama admin merupakan halaman yang ditampilkan ketika admin telah selesai melakukan proses login.

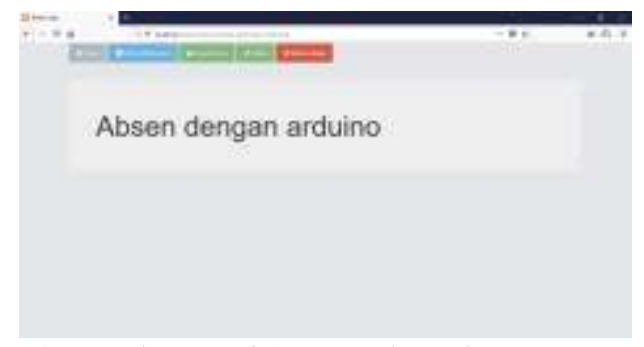

Gambar 19 Impelementasi Antar Muka Halaman Utama Admin

c. Implementasi Antar Muka Halaman Utama Dosen. Implementasi halaman utama Dosen merupakan halaman yang ditampilkan ketika Dosen telah selesai melakukan proses login.

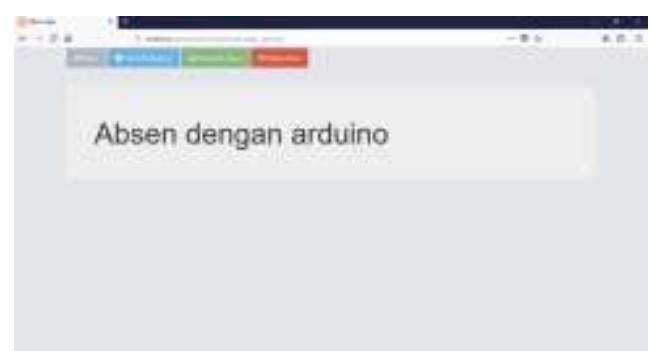

Gambar 20 Impelementasi Antar Muka Halaman Utama Dosen

d. Implementasi Antar Muka Halaman Pendaftaran Kartu Id Card. Implementasi halaman Pendaftaran Dosen dan Mahasiswa merupakan halaman yang ditampilkan ketika Admin yang akan melakukan pendaftaran kartu Id Card.

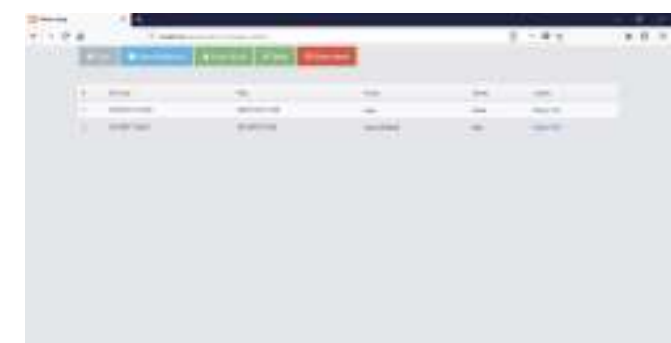

Gambar 21 Impelementasi Antar Muka Halaman Pendaftaran Kartu Id Card

e. Implementasi Antar Muka Halaman Data Absensi Dosen. Implementasi halaman Data Absensi Dosen merupakan halaman yang ditampilkan ketika Admin akan melakukan pengecekan data absensi.

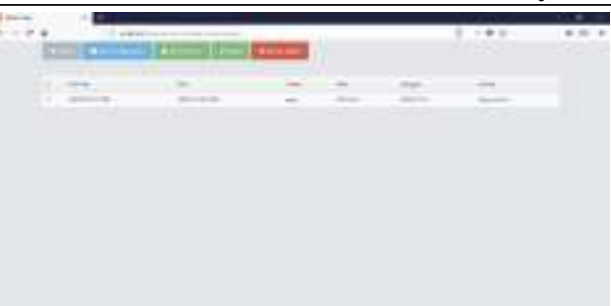

Gambar 22 Impelementasi Antar Muka Halaman Data Absensi Dosen

f. Implementasi Antar Muka Halaman Data Absensi Mahasiswa. Implementasi halaman Data Absensi Mahasiswa merupakan halaman yang ditampilkan ketika Admin akan melakukan pengecekan data absensi.

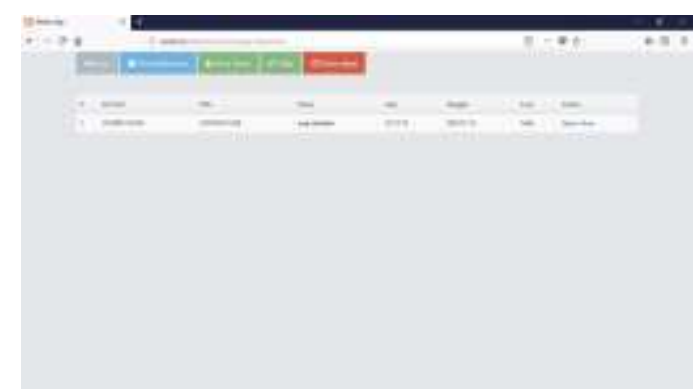

Gambar 23 Impelementasi Antar Muka Halaman Data Absensi Mahasiswa

g. Implementasi Antar Muka Halaman Ubah Data. Implementasi halaman ubah data merupakan halaman yang ditampilkan ketika Admin akan melakukan pengubahan data .

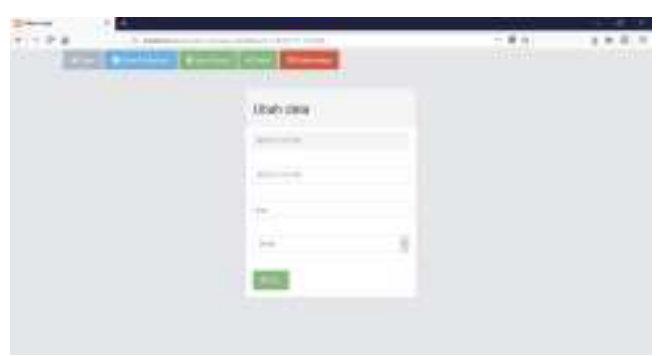

Gambar 24 Impelementasi Antar Muka Halaman Ubah Data

h. Implementasi Antar Muka Halaman Data Absensi Mahasiswa. Implementasi halaman Data Absensi Mahasiswa merupakan halaman yang ditampilkan ketika Dosen akan melakukan pengecekan .

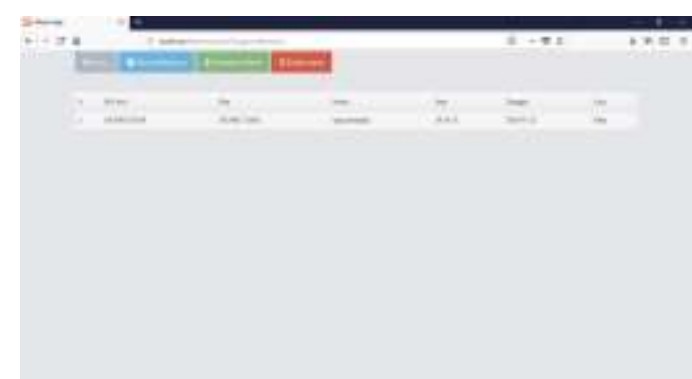

Gambar 25 Impelementasi Antar Muka Halaman Data Absensi Mahasiswa

\subsection{Perakitan Arduino Sistem Pengelolaan Absensi Mahasiswa}

a. Perakitan Arduino Uno dan Ethernet Shield 


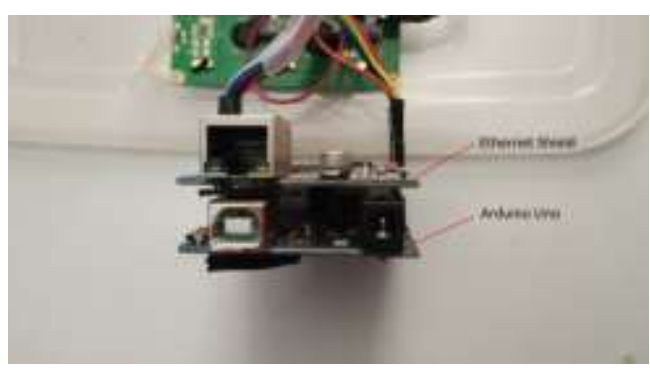

Gambar 26 Perakitan Arduino Uno dan Ethernet Shield

Gambar 26 Perakitan Arduino uno dan Ethernet shield sebagai otak dari prototipe sistem pengelolaan absensi mahasiswa dimana nantinya ketika sistem di nyalakan, maka Arduino uno dan Ethernet shield akan menintegrasikan perintah ke setiap modul dan sensor yang terhubung.

b. Perakitan Modul Radio Frequensi Identification (RFID)

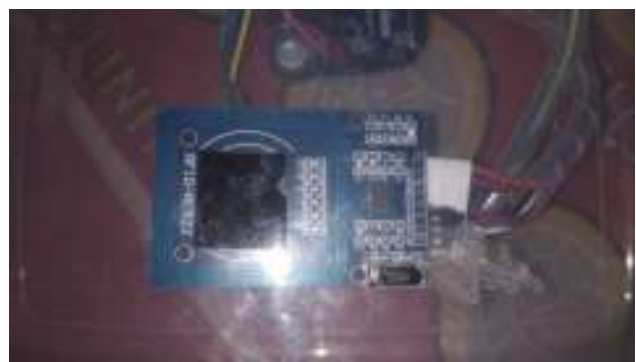

Gambar 27 Perakitan Modul Radio Frequensi Identification (RFID)

Gambar 27 Perakitan Modul Radio Frequensi Identification (RFID), dimana nantinya RFID ini menerima inputan dari hasil scan kartu RFID yang terdaftar kemudian diteruskan ke bagian server.

\section{c. Perakitan LCD 16x2(Liquid Crystal Display)}

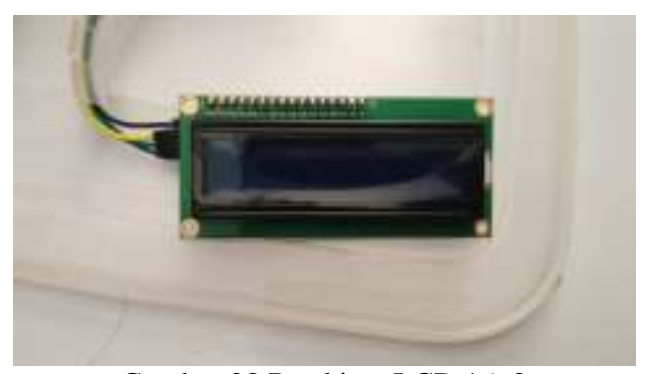

Gambar 28 Perakitan LCD 16x2

Gambar 28 Perakitan LCD (Liquid Crystal Display), dimana LCD dapat menginformasikan status absensi mahasiswa dan dosen.

\section{d. Kabel RJ-45}

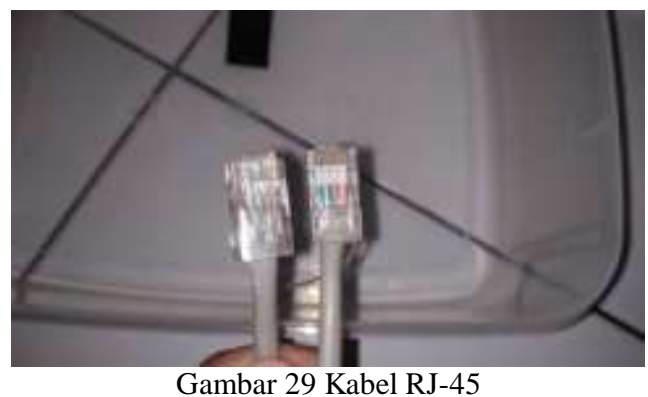

Gambar 29 Kabel RJ-45, berfungsi untuk mengalirkan arus data inputan kebagian server.

e. Kartu RFID

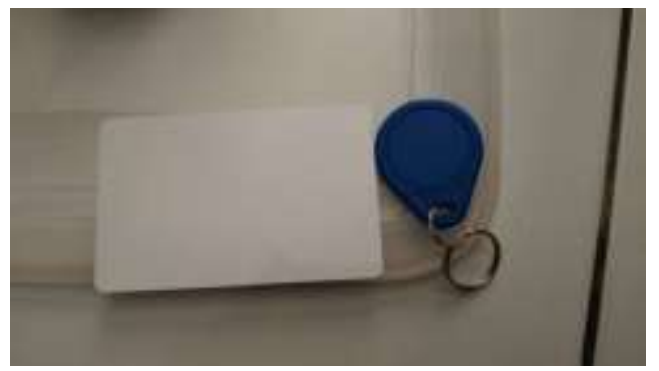

Gambar 30 Kartu RFID

Gambar 30 Kartu RFID, digunakan untuk proses absensi Mahasiswa dan Dosen.

\section{Simpulan}

Bedasarkan hasil penelitian, perancangan dan implementasi yang dilakukan, dapat diambil beberapa kesimpulan, antara lain :

- Dengan adanya alat Sistem Pengelolaan Absensi Mahasiswa Berbasis Microcontroller Arduino dapat meningkatkan keakuratan waktu pengecekan absensi tersebut .

- Dengan adanya alat Sistem Pengelolaan Absensi bagian admin bisa lebih mudah dalam pengecekan absen harian.

- Jadi setelah adanya alat ini bisa menghemat waktu dan pengularan biaya untuk kertas absensi.

- Jadi untuk yang akan datang ketika mahasiswa sudah memasuki dunia kerja bisa lebih disiplin dalam waktu masuk kerja.

\section{Saran}

Pada penelitian ini terdapat beberapa saran untuk meningkatkan kinerja dari hasil peracangan monitoring absensi yang dibangun.

- Dilakukan pengembangan dari segi insfrastuktur agar dapat lebih membantu dalam dalam proses monitoring absensi mahasiswa.

- Pengembangan Prototipe Sistem Monitoring Absensi Mahasiswa ini di integrasikan dengan Sistem Informasi lainnya.

- Pengembangan Prototipe Sistem Monitoring Absensi 
Mahasiswa ini perlu dikembangkan lagi terutama dalam penggunaan sensor dan modul yang lebih bagus.

\section{Daftar Pustaka}

[1] Arduino. (2015). Retrieved June 22, 2017, from https://www.Arduino.cc/en/Reference/HomePage. Diambil kembali dari www.Arduino.cc.

[2] Heri, A \& Aan, D.(2017). "Arduino Belajar Cepat dan Pemograman".Bandung: Informatika Bandung.

[3] Eko B,S \& Bobi kurniawan 2015. "Jurnal". Perancangan Sistem Absensi Kehadiran Perkuliahan dengan Menggunakan Radio Frequency Identification (RFId).

[4] Ardianto,P.Syaiful,N,A.Yusnidah."Jurnal".2 Mei 2015.Perancangan Prototipe Sistem Parkir Cerdas Berbasis Mikrokontroler Atmega8535.

[5] Djuanda, F. (2011). Pengenalan Arduino. Jakarta: Elexmedia.

[6] Djuanda, F. (2011, January 8). TOBUKU.COM. Retrieved June 22, 2017, from http://tobuku.com/index.php/2011/01/08/ pengenalan-Arduino/

[7] Juhana, D. M. (2001). Servis dan Reparasi Mobil. Pustaka Grafika.

[8] Priyanto,H \& Jauhari K,K. (2017). Pemograman Web . Bandung: Informatika Bandung.

[9] Pressman, R. S. (2010). Software Engineering (7 ed.). Newyork: McGraw Hill.

[10] Santoso, H. (2015). Panduan Praktis Arduino Untuk Pemula V.1. Jakarta: Elang Sakti.

[11] Banzi, Massimo. "Gettting Started with Arduino". O'Reilly. 2008

[12] Daryanto (1997). "kamus Indonesia lengkap". Surabaya 